\title{
Radiolabeled tirofiban - a potential radiopharmaceutical for detection of deep venous thrombosis
}

This article was published in the following Dove Press journal:

Drug Design, Development and Therapy

21 September 2016

Number of times this article has been viewed

\author{
Marija Darkovska- \\ Serafimovska ${ }^{1,5}$ \\ Emilija Janevik-Ivanovska' \\ Icko Djorgoski² \\ Zorica Arsova- \\ Sarafinovska ${ }^{1,3}$ \\ Milka Zdravkovska' \\ Trajan Balkanov ${ }^{4}$ \\ Nenad Ugresic ${ }^{5}$ \\ 'Department of Pharmacy, Faculty \\ of Medical Sciences, Goce Delcev \\ University, Stip, ${ }^{2}$ Department of \\ Physiology, Faculty of Natural \\ Sciences and Mathematics, Ss Cyril \\ and Methodius University in Skopje, \\ ${ }^{3}$ Department of Quality Control \\ of Medicines, Institute for Public \\ Health of the Republic of Macedonia, \\ ${ }^{4}$ Department of Pharmacology and \\ Toxicology, Faculty of Medicine, \\ Ss Cyril and Methodius University in \\ Skopje, Skopje, Republic of Macedonia; \\ ${ }^{5}$ Department of Pharmacology, Faculty \\ of Pharmacy, University of Belgrade, \\ Belgrade, Serbia
}

Aim: The aim of this study was to investigate the possibility of using ${ }^{99 m}$ technetium ${ }^{(99 \mathrm{~m} T c)}$ )-labeled tirofiban (a reversible antagonist of glycoprotein IIb/IIIa) for detection of deep venous thrombosis (DVT) in rats without causing an antiplatelet effect.

Methods: The ability of in vitro tirofiban to inhibit adenosine $5^{\prime}$-diphosphate (ADP)-induced platelet aggregation was evaluated using optical aggregometer. Binding of ${ }^{99 \mathrm{~m}} \mathrm{Tc}$-tirofiban to platelets was evaluated. Serum levels of unlabeled (a validated high performance liquid chromatography method) and ${ }^{99 \mathrm{~m}} \mathrm{Tc}$-tirofiban after single intravenous injection were evaluated in male Wistar rats with or without induced DVT (femoral vein ligation model), and the rats were also subjected to whole body scintigraphy.

Results: Tirofiban in vitro inhibits ADP-induced aggregation of human platelets in a dose- and concentration-dependent manner $(10 \mathrm{nM}$ to $2 \mu \mathrm{M})$, but only if it is added before ADP and not after ADP. ${ }^{99 \mathrm{~m} T c}$ labeling did not affect the ability of tirofiban to bind to either human or rat platelets, nor did it affect tirofiban pharmacokinetics in intact rats or in animals with induced DVT. When ${ }^{99 \mathrm{~m}}$ Tc-tirofiban was injected to rats after induction of DVT, at a molar dose lower than the one showing only a weak antiaggregatory effect in vitro, whole body scintigraphy indicated localization of ${ }^{99 \mathrm{~m}}$ Tc-tirofiban around the place of the induced DVT.

Conclusion: ${ }^{99 \mathrm{~m}} \mathrm{Tc}$ labeling of tirofiban does not affect its ability to bind to glycoprotein IIb/IIIa or its in vivo pharmacokinetics in rats, either intact or with DVT. A low, nonantiaggregatory dose of ${ }^{99 m}$ Tc-tirofiban may be used to visualize DVT at an early stage.

Keywords: tirofiban, ${ }^{99 m}$ technetium, deep venous thrombosis, visualization

\section{Introduction}

Platelets play an important role in pathological thrombus formation, particularly within atherosclerotic arteries subjected to a high shear stress, ${ }^{1}$ and in the regulation of immune responses, cancer metastasis, vascular development, and angiogenesis. ${ }^{2-4}$ Binding of plasma fibrinogen to activated platelet glycoprotein (GP) IIb/IIIa receptors is a prerequisite and an important event in platelet aggregation and therefore in thrombus formation, regardless of the type of platelet stimulus. One way to inhibit platelets is to block the platelet membrane GPIIb/IIIa receptor, which binds circulating fibrinogen or von Willebrand factor and cross-links platelets at the final common pathway to platelet aggregation. ${ }^{5-7}$

Tirofiban ( $\mathrm{N}$-(methylsulfonyl)-4-O-(4-(4-piperidinyl)-L-tyrosine) is a nonpeptide derivative of tyrosine, highly selective, short-acting inhibitor of fibrinogen binding to the platelet GPIIb/IIIa receptor. As a molecule with a small molecular weight and simple chemical structure, tirofiban provides the possibility to be used as a radiolabeled
Correspondence: Emilija JanevikIvanovska

Department of Pharmacology, Faculty of Medical Sciences, Goce Delcev University, "Krste Misirkov" I0-A. P.O 20I, Stip - 2000, Republic of Macedonia Tel +38975374805

Email emilija.janevik@udg.edu.mk 
potential radiopharmaceutical to inject in the patient without the risk of the occurrence of immune reactions after administration. The size and structure are also important parameters for its fast elimination from the body. Tirofiban binds GPIIb/IIIa receptors in the same way as fibrinogen ${ }^{8,9}$ and can be seen only in the active clot. This phenomenon indicates the difference between acute and chronic blood clot and can be used as an advantage for vizualization.

When administered intravenously, tirofiban inhibits ex vivo platelet aggregation in a dose- and concentrationdependent manner. The extent of this inhibition is proportional to the concentration of tirofiban in plasma. ${ }^{10-12}$ In combination with heparin, it is used for treatment of acute coronary syndrome (in patients who are to be managed medically or those undergoing angiography/coronary intervention). ${ }^{13,14}$ Platelet aggregation inhibition ${ }^{6}$ is reversible following cessation of the infusion of tirofiban. Tirofiban also activates growth-stimulatory signals in the endothelium. ${ }^{8}$ As a nonpeptide tyrosine derivative, tirofiban has a rapid onset and short duration of action when administered intravenously, with a half-life of $\sim 2$ hours. This qualifies it as a potential radiopharmaceutical for the detection of deep venous thrombosis (DVT) with more desirable properties compared to other platelet aggregation inhibitors, eg, monoclonal antibodies (abciximab) and peptides containing Arg-Gly-Asp (RGD) or Lys-Gly-Asp (KGD) sequences (eptifibatide), which have been developed in the recent years. With tirofiban, $90 \%$ inhibition of platelet aggregation is achieved by the end of a 30-minute infusion. ${ }^{15,16}$ Tirofiban is cleared from the plasma largely via kidneys. The plasma protein binding is concentration independent (over the range of $0.01-25 \mu \mathrm{g} / \mathrm{mL}$ ), with the unbound fraction of $\sim 35 \%$. The steady-state volume of distribution ranges from $22 \mathrm{~L}$ to $42 \mathrm{~L} \cdot{ }^{15-17}$

The idea to formulate radioactive tirofiban using ${ }^{99 \mathrm{~m}}$ technetium $\left({ }^{99 \mathrm{~m}} \mathrm{Tc}\right)$ as a radioisotope for labeling and for diagnostic purpose was generated following the demand to detect primary pathological deviations in the blood vessels, to identify the localization of the new fresh thrombus, and to define its morphological characteristics.

Tirofiban antiplatelet action is of a great potential value in experimental medicine, particularly its potential use as an imaging radiopharmaceutical. In a previous study, we developed and validated a high performance liquid chromatography (HPLC) method with ultraviolet (UV) detection for determination of tirofiban in serum. ${ }^{18}$ In the present study, we aimed to verify whether the introduction of radioactive technetium in the molecule of tirofiban will lead to changes in the affinity of tirofiban to bind the GPIIb/IIIa receptors and to identify the in vitro concentration of tirofiban with minimal antiplatelet activity that could be converted into an in vivo dose of ${ }^{99 \mathrm{~m}} \mathrm{Tc}$-tirofiban and use it to visualize early DVT in the rat.

\section{Methods Ethics}

This study was approved by the ethics committee of the Faculty of Natural Sciences and Mathematics, Ss Cyril and Methodius University in Skopje. All animal experiments were conducted in accordance with the law and guidelines on the protection and welfare of animals and the law for the ratification of the European Convention for the Protection of Vertebrate Animals used for experimental and other scientific purposes. Human blood used for in vitro analysis was obtained from healthy volunteers who provided a signed informed consent.

\section{Experimental animals}

We used healthy male Wistar rats (six per experimental group), because of their sensitivity and behavioral similarities as in humans, weighing 225-250 g, and kept six per cage, at $22^{\circ} \mathrm{C}$, under a $12: 12$ hours light-dark schedule with food and water ad libitum.

\section{Chemicals}

Tirofiban hydrochloride was purchased from Merck Sharpe\&Dhome (USA) (Aggrastat ${ }^{\circledR}$, batch no L-000700462006X027), adenosine 5'-diphosphate (ADP) was purchased from Sigma-Aldrich Co. (St Louis, MO, USA), methanol and acetonitrile of HPLC grade were obtained from SigmaAldrich Co., and all other reagents were of analytical grade. Redistilled water was used to prepare the HPLC mobile phase solutions. ${ }^{99 \mathrm{~m}} \mathrm{Tc}$ was obtained from a Mo99/Tc $99 \mathrm{~m}$ generator system ELUMATIC III-CIS-bio (IBA Molecular, France) $16 \mathrm{GBq}$ as a solution of sodium pertechnetate in $0.9 \%$ sodium chloride with a specific activity of $370-555 \mathrm{MBq} / 5 \mathrm{~mL}$.

\section{Preparation of human and rat platelets}

Rat blood samples were collected from the carotid vein using a syringe containing $3.3 \%(\mathrm{w} / \mathrm{v})$ sodium citrate. The ratio of blood and sodium citrate was 10:1 in order to obtain effective separation of the platelets and to prevent coagulation. Following the incubation period, blood was mounted on a hemacytometer. The cells were allowed to settle and were counted in a specific area of the hemacytometer chamber under a microscope. Platelet numbers varied from $3.6 \times 10^{8} / \mathrm{mL}$ to $5.4 \times 10^{8} / \mathrm{mL}$. Blood from five healthy volunteers was obtained from the cubital vein using a syringe 
containing $3.3 \%(\mathrm{w} / \mathrm{v})$ sodium citrate. The ratio of blood, sodium citrate, and hydroxyethyl starch was 5:1:0.5 in order to obtain effective separation of the platelets and to prevent coagulation. To prepare washed platelets, plateletrich plasma (PRP) suspension was acidified to $\mathrm{pH} 6.5$ with $1 \mathrm{M}$ citric acid; the sample was centrifuged at $1,500 \times \mathrm{g}$ for 20 minutes to obtain pellets, which were resuspended in a $\mathrm{Ca}^{2+}$-free Tyrode Hepes buffer $(152 \mathrm{mM} \mathrm{NaCl}, 2.8 \mathrm{mM} \mathrm{KCl}$, $8.9 \mathrm{mM} \mathrm{NaHCO}_{3}, 0.8 \mathrm{mM} \mathrm{KH}_{2} \mathrm{PO}_{4}, 0.8 \mathrm{mM} \mathrm{MgCl}_{2}, 5.6 \mathrm{mM}$ glucose, apyrase [2 U/mL], $10 \mu \mathrm{M}$ EDTA, BSA $[3.5 \mathrm{mg} / \mathrm{mL}]$, and $10 \mathrm{mM}$ Hepes, $\mathrm{pH}$ 6.5). Platelets were washed once with the above buffer and finally suspended in the same buffer with the exception that, in the final suspension medium, apyrase and EDTA were omitted, and $\mathrm{pH}$ was adjusted to 7.4. Platelet concentration was standardized to $2-3 \times 10^{8}$ cells $/ \mathrm{mL}$ by dilution with Tyrode Hepes buffer.

\section{In vitro evaluation of platelet aggregation}

Platelet aggregation was assessed using a Carat TX4 optical platelet aggregometer (Carat Diagnostic Ltd, Hungary) as the percent change in light transmission (over 5 minutes, maximum voltage $25 \mathrm{~mA}$ ). Platelet mass $(450-475 \mu \mathrm{L}$ per assay) was prepared from saline-washed PRP (to preserve isotonicity and prevent interference of cell-free plasma) using acid citrate dextrose (ACD; ACD-to-PRP ratio 1\%:10\%) with the addition of $10 \%$ calcium chloride (final $\mathrm{Ca}^{2+}$ concentration in the medium $100 \mathrm{mM}$ ) to immobilize ACD. Spontaneous aggregation was assessed using platelet poor plasma as a control without platelet count adjustments. Induced aggregation was assessed by adding ADP (in a volume of $25 \mu \mathrm{L}$ ) at concentrations of $1.0 \mu \mathrm{M}, 10 \mu \mathrm{M}$, or $100 \mu \mathrm{M}$. The procedure was carried out in three phases: 1) preparation of the baseline by determination of the " 0 " point voltage measuring cell-free plasma, 2) voltage measurement of PRP in order to get the maximum voltage, and 3) determination of the stimulated aggregation. ${ }^{19}$ Inhibition by tirofiban (concentration range $10 \mathrm{nM}$ to $2 \mu \mathrm{M}$ ) of platelet aggregation induced by $10 \mu \mathrm{M}$ ADP was performed with cell-free plasma as a control. ${ }^{20-22}$ The process of aggregation was assessed by an optical aggregometer as voltage change (\%) indicating the presence of formed aggregates as a function of time.

\section{Freeze drying preparation of ready to use kit of the radiopharmaceutical formulation}

Freeze drying preparation of ready to use kit of tirofiban formulation was performed in a vacuum and nitrogen atmosphere (Labconco Freezone Stoppering Tray Dryer, USA). Tirofiban makes a stable complex with diethylene triamine

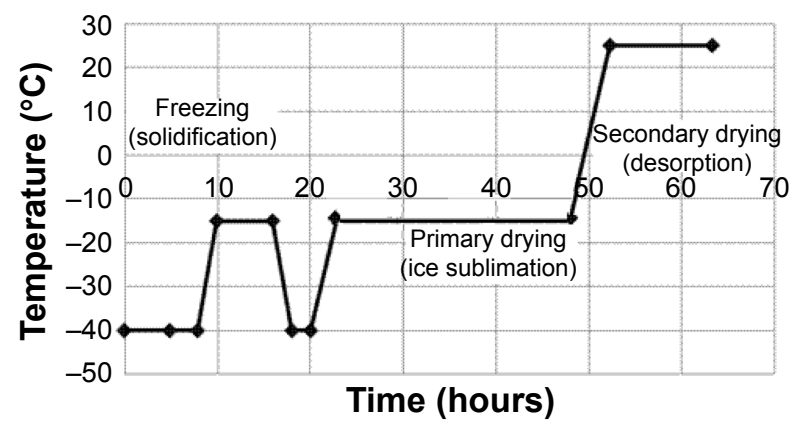

Figure I Diagram of freeze drying process.

pentaacetic acid. ${ }^{23,24}$ Tin chloride was used as a reducing agent for ${ }^{99 \mathrm{~m}} \mathrm{Tc}$. The ratio of tirofiban and tin chloride was 1:2. Freeze drying process started with direct freezing at an initial temperature of $-40^{\circ} \mathrm{C}$. The whole process lasted 23 hours, including a diagram of the program (Figure 1), which had a primary freezing for 1 hour at $-4^{\circ} \mathrm{C}$, and then the temperature was increased from $-40^{\circ} \mathrm{C}$ to $-15^{\circ} \mathrm{C}$ by $0.20^{\circ} \mathrm{C} / \mathrm{min}$, once again cooled to $-40^{\circ} \mathrm{C}$ and kept for 2 hours. Primary drying was conducted at $-10^{\circ} \mathrm{C}$ with a heating speed of $0.15^{\circ} \mathrm{C} / \mathrm{min}$, while secondary drying was done at $25^{\circ} \mathrm{C}$ with a heating speed of $0.15^{\circ} \mathrm{C} / \mathrm{min}$ and a vacuum of 0.280 Torr. The finished product was stored well closed at $2{ }^{\circ} \mathrm{C}-6^{\circ} \mathrm{C}$ and used for labeling with ${ }^{99 \mathrm{~m}} \mathrm{Tc}$.

\section{Labeling of tirofiban with ${ }^{99 \mathrm{~m} T \mathrm{~T}}$}

Labeling of tirofiban with technetium in the form of pertechnetate $\left.{ }^{99 \mathrm{~m}^{\mathrm{TcO}} 4}{ }^{-}\right)$with the activity of $10-15 \mathrm{mCi}$ (370-555 MBq) was carried out using the method of direct labeling under nitrogen, in sterile conditions, on the freezedried preparation. The incubation mixture was left over 15 minutes at room temperature with occasional stirring. The quality of the labeled product was tested using instant thin layer chromatography, and the percentage of the yield was always $>95$. Specific activity of the final product was $370-555 \mathrm{MBq} / \mathrm{mL}$.

\section{In vitro binding of ${ }^{99 \mathrm{~m}} \mathrm{Tc}$-tirofiban to rat and human platelets}

Apart from citrate contained in the blood-withdrawal tubes, no other anticoagulant was used. Blood was centrifuged for 10 minutes at $1,500 \times g$, and PRP was separated. ${ }^{99 \mathrm{~m}} \mathrm{Tc}-$ tirofiban with the activity of $1.7 \times 10^{5} \mathrm{cpm}$ (in a volume of $40 \mu \mathrm{L})$ and $0.9 \% \mathrm{NaCl}(810 \mu \mathrm{L})$ were added to $1 \mathrm{~mL}$ of PRP $\left(2-3 \times 10^{8}\right.$ cells $/ \mathrm{mL}$; counted manually as described), and the mixture was incubated over 10 minutes at room temperature and centrifuged again to remove the unbound radioactivity. Unbound radioactivity was further removed by 
washing the platelets twice with $0.9 \% \mathrm{NaCl}$ (centrifugation after each washing), and platelet-bound radioactivity was measured using a dose calibrator. All experiments were done in triplicate.

\section{Experimental model of DVT}

Rats were randomly assigned to undergo venous thrombosis induction by ligation of the femoral vein $(n=18)^{13,18}$ under anesthesia (thiopental sodium $20 \mathrm{mg} / \mathrm{kg}$ bw, intraperitoneally) or to serve as controls $(n=18)$. Hypercoagulability of blood was achieved by intravenous administration of $0.2 \mathrm{~mL}$ of tissue thrombin. ${ }^{25,26}$

\section{Serum concentrations of unlabeled and ${ }^{99 \mathrm{~m} T c}$-tirofiban in rats with and without DVT}

Animals were anesthetized throughout these 60-minute experiments. Unlabeled tirofiban hydrochloride (in $0.9 \%$ $\mathrm{NaCl}$ ) was injected as iv (tail vein) bolus dose $(0.6 \mathrm{mg} / \mathrm{kg})$, and blood was withdrawn $(0.3 \mathrm{~mL}$ into heparinized tubes $)$ in 15-minute intervals. Samples were centrifuged at 3,500 rpm for 5 minutes, methanol was added (serum:methanol 1:3, v/v) for protein precipitation, and samples were centrifuged once again at 3,500 rpm over 5 minutes. The obtained serum was analyzed for tirofiban concentrations using a previously developed HPLC method with UV detection. ${ }^{18,27}$ In brief, we used a Perkin Elmer Series 200 chromatographic system. The analyte separation was carried out at ambient temperature on a reversed-phase LiChrospher ${ }^{\circledR} 100$ RP-18 column $(4.0 \times 250 \mathrm{~mm}, 5 \mu \mathrm{m}$ particle size) (Merck Millipore, Billerica, MA, USA) using the isocratic mode. The mobile phase consisted of a mixture of $0.1 \mathrm{M} \mathrm{KH}_{2} \mathrm{PO}_{4}$ ( $\mathrm{pH}$ 5.0, adjusted with $1.0 \mathrm{~N}$ sodium hydroxide solution) and acetonitrile in the ratio of $80 \%: 20 \%(\mathrm{v} / \mathrm{v})$ with a flow rate of $1.0 \mathrm{~mL} / \mathrm{min}$. The UV detector was set at a wavelength of $274 \mathrm{~nm} .{ }^{18,27}$ 99m Tc-tirofiban was injected as a bolus iv dose

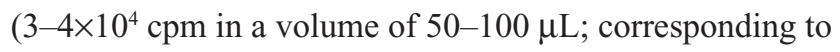
$2.0 \mathrm{nmol}$ of tirofiban), and blood samples were taken in the same way as with unlabeled tirofiban.

\section{Imaging studies}

Imaging studies were completed after iv administration of ${ }^{99 m}$ Tc-tirofiban $\left(3-4 \times 10^{4} \mathrm{cpm}\right.$ in a volume of $50-100 \mu \mathrm{L}$, corresponding to $2.0 \mathrm{nmol}$ of tirofiban) using a gamma camera with high resolution ("Sopha Medical” SPECT camera with a single detector, 64 positions, 30 steps, $64 \times 64$ bits, and rotation of $\left.360^{\circ}\right)^{28}$ at 1 hour and 6 hours after injection. Rats were anesthetized (thiopental sodium) throughout the study.

\section{Data analysis}

Data were expressed as mean \pm standard deviation. Kolmogorov-Smirnov test and Shapiro-Wilk's $W$ test were used to identify the distribution of variables. Nonparametric statistical methods were used for the heterogeneous variables. Mann-Whitney $U$-test was used to compare data on ${ }^{99 \mathrm{~m}}$ Tc-tirofiban binding to human and rat platelets. Friedman ANOVA and Wilcoxon matched pairs test for dependent samples and Mann-Whitney $U$-test for independent samples were used to compare data on the mean serum concentrations of unlabeled and of ${ }^{99 \mathrm{~m}} \mathrm{Tc}$-tirofiban over 60 minutes after intravenous injection in rats without or with induced DVT. A $P$-value of $<0.05$ was considered statistically significant.

Kinetica 4.1 (InnaPhase Corp) was used to calculate elimination half-lives (by noncompartmental method) of unlabeled and ${ }^{99 m}$ Tc-tirofiban. Scintigraphic images were processed by computer program "Sopha Medical," which is a part of the gamma camera.

\section{Results}

\section{Effect of tirofiban in vitro on ADP- induced aggregation of human platelets}

Addition of ADP $(1 \mu \mathrm{M}, 10 \mu \mathrm{M}$, or $100 \mu \mathrm{M})$ to human platelets in vitro $\left(2.41-2.48 \times 10^{8}\right.$ cells $\left./ \mathrm{mL}\right)$ induced platelet aggregation, most profoundly at $10 \mu \mathrm{M}$ (Figure 2A). Pretreatment of the platelets with tirofiban $(10 \mathrm{nM}$ to $2 \mu \mathrm{M})$ concentration dependently inhibited the effect of $10 \mu \mathrm{M}$ of ADP (Figure 2B), with the lowest concentration of tirofiban $(10 \mathrm{nM})$ producing only a slight effect. Moreover, the inhibitory effect of $10 \mathrm{nM}$ of tirofiban existed only when it was added before ADP (1-5 minutes before) or at the same time with ADP, but not when it was added after ADP (practically no inhibition was observed when added 30 seconds after ADP) (Figure 2C). This indicated that an in vivo dose of tirofiban that would yield systemic concentrations $\leq 10 \mathrm{nM}$ and particularly if injected after induction of DVT would not produce any relevant antiaggregatory effect.

\section{${ }^{99 \mathrm{~m}}$ Tc labeling does not prevent binding of tirofiban to human or rat platelets in vitro} After 10 minutes incubation of the rat or human platelets $\left(2-3 \times 10^{8}\right.$ cells $\left./ \mathrm{mL}\right)$ with ${ }^{99 \mathrm{~m}}$ Tc-labeled tirofiban (nominal activity $1.7 \times 10^{5} \mathrm{cpm}$; actually added to rat platelets [n=6] 173,785-180,991 cpm; and actually added to human platelets [n=6] 171,349-182,006 cpm) and after thorough washing (twice) of the platelets with $0.9 \% \mathrm{NaCl}, 59.6 \% \pm 2.1 \%$ 
A

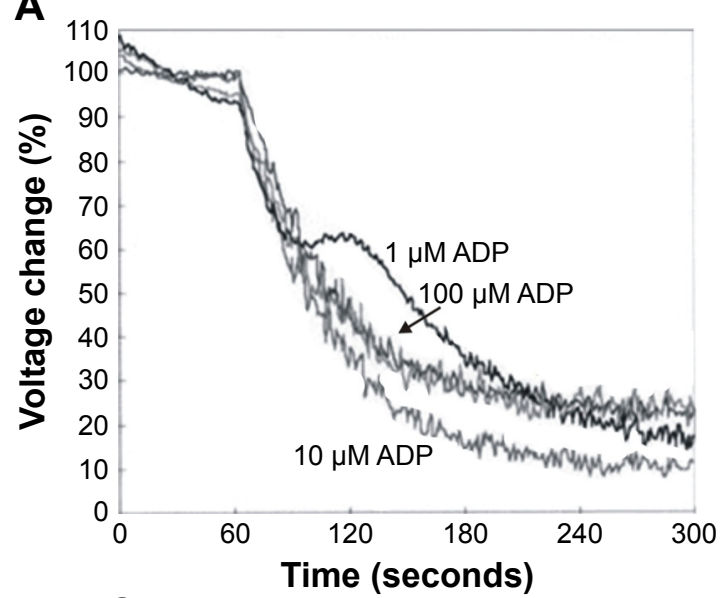

C
B



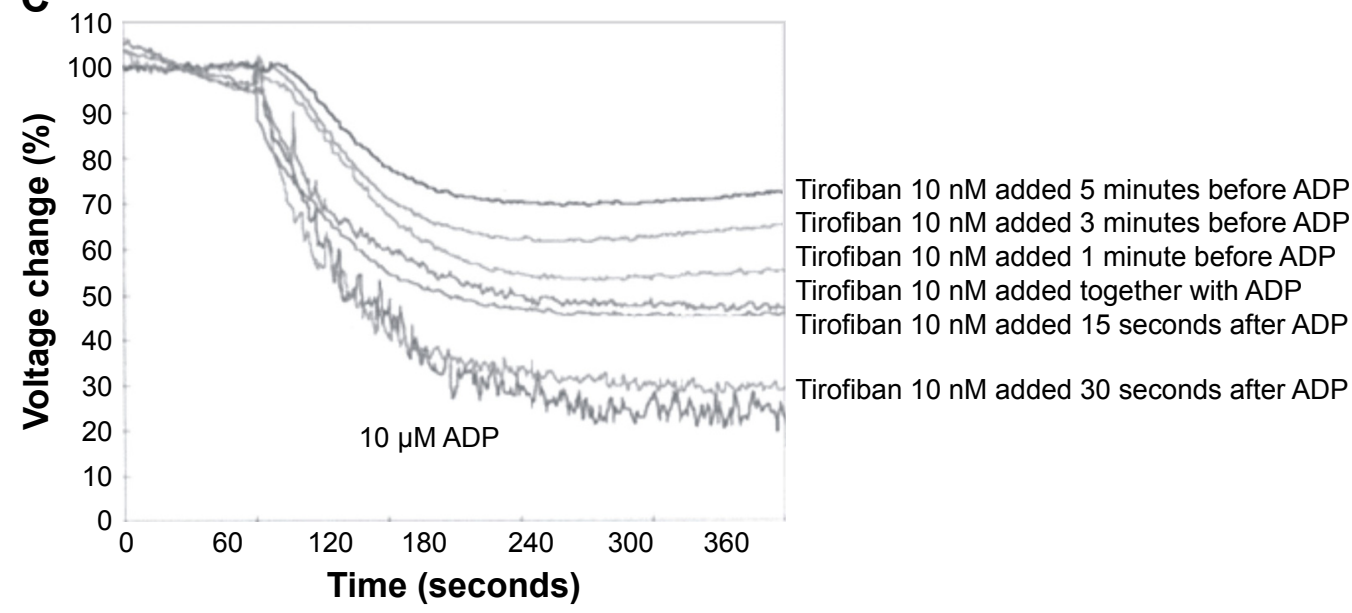

Figure 2 Effect of in vitro Tf on ADP-induced aggregation of human platelets.

Notes: (A) Effect of ADP (I $\mu \mathrm{M}, 10 \mu \mathrm{M}$, or $100 \mu \mathrm{M})$. (B) Inhibition of the effect of $10 \mu \mathrm{M}$ of ADP by increasing the concentrations of Tf (I0 nM to $2 \mu \mathrm{M})$. (C) Inhibition by $10 \mathrm{nM}$ of Tf of the ADP effect in respect to the timing of Tf addition. Suspended human platelets (450-475 $\mu \mathrm{L})$ were incubated with ADP with or without Tf for 5 minutes. Abbreviations: ADP, adenosine diphosphate; Tf, tirofiban.

and $57.4 \% \pm 1.6 \%$ of the added radioactivity, respectively ( $P=0.065$ for the difference between human and rat platelets), were recovered bound to platelets indicating that ${ }^{99 \mathrm{~m}} \mathrm{Tc}$ labeling did not prevent binding of tirofiban to platelets.

\section{${ }^{99 m}$ Tc labeling does not affect the decline of the systemic tirofiban concentrations}

Serum concentrations of both the unlabeled tirofiban $(0.6 \mathrm{mg} / \mathrm{kg})$ (Figure $3 \mathrm{~A})$ and ${ }^{99 \mathrm{~m}} \mathrm{Tc}$-tirofiban $\left(3-4 \times 10^{4} \mathrm{cpm}\right.$ in a volume of $50-100 \mu \mathrm{L}$, corresponding to $2.0 \mathrm{nmol}$ of tirofiban) (Figure 3B) similarly rapidly declined upon intravenous injections, comparably so in animals with DVT and without DVT.

There are statistically significant differences between mean concentrations of tirofiban in serum $(\mathrm{mg} / \mathrm{L})$, in the group of rats with DVT (N1) (Friedman ANOVA chi-square $=30.06$, $P<0.001$ ) and in the group of rats without DVT (N2) (Friedman ANOVA chi-square $=28.38, P<0,001)$, within the specified time intervals, after injected dose of $0.6 \mathrm{mg} / \mathrm{kg}$. In the studied group of rats without DVT (N2), no significant difference between the concentrations of tirofiban in serum was observed only after 45 minutes and 60 minutes (Wilcoxon matched pairs test: $P=0.2736$ ). According to Mann-Whitney $U$-test (between groups N1 and N2), the difference is not significant between the measured concentrations, only after 30 minutes $(P=0.6359)$ (Figure 3A).

Regarding the elimination of nonradioactive tirofiban between the groups (N1 and N2), there is no significant difference $(P=0.1370)$. Regarding the elimination of radioactive tirofiban between the groups (N1 and N2), the differences are significant for $P=0.0001$ (significantly longer is the time of radioactivity in the group without DVT) (Figure 3B).

\section{Whole body scintigraphy}

At 1 hour and 6 hours after an iv injection of ${ }^{99 \mathrm{~m}} \mathrm{Tc}$-tirofiban (tail vein) $\left(3-4 \times 10^{4} \mathrm{cpm}\right.$ in a volume of $50-100 \mu \mathrm{L}$, 

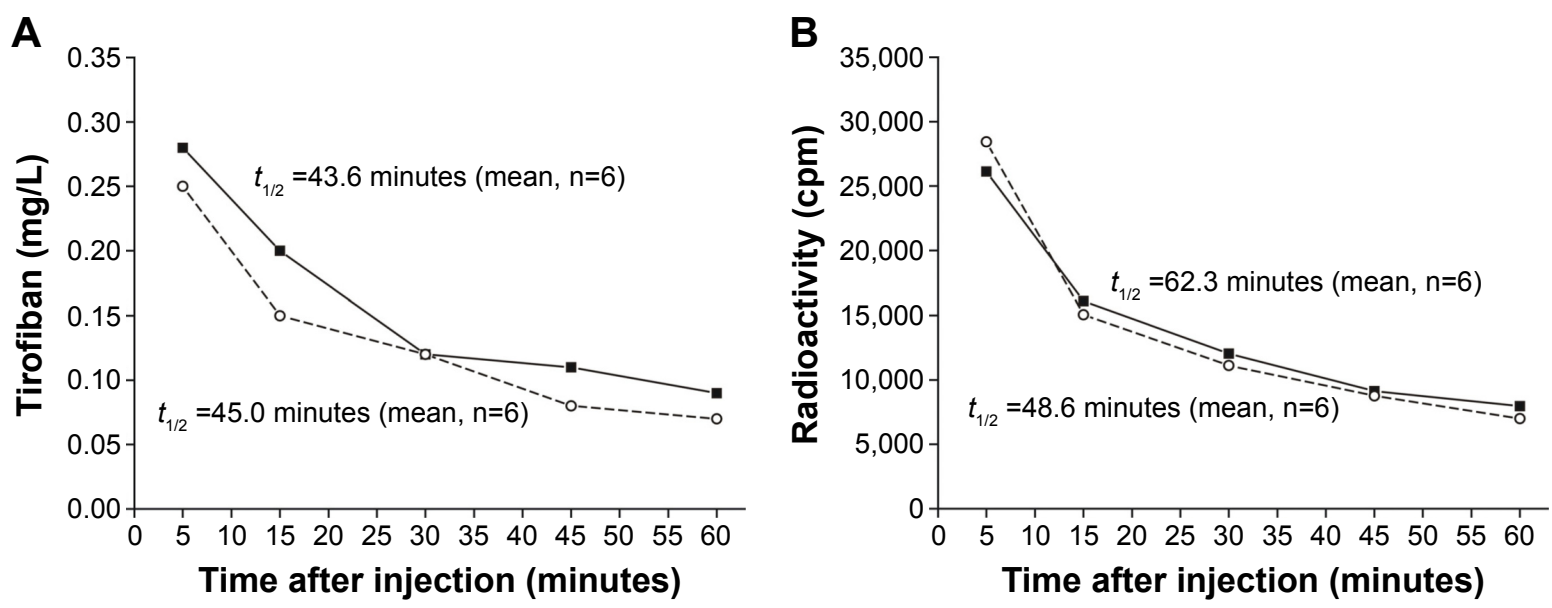

- - No DVT (control) -o- DVT

Figure 3 Mean serum concentrations of unlabeled (A) and of ${ }^{99 m}$ Tc-tirofiban (B) over 60 minutes after intravenous injection in rats without or with induced DVT. Notes: (A) Rats ( $\mathrm{n}=6 /$ group) were injected (tail vein) with unlabeled tirofiban $(0.6 \mathrm{mg} / \mathrm{kg}$ ), and serum concentrations ( $\mathrm{mg} / \mathrm{L})$ were determined by a validated high performance

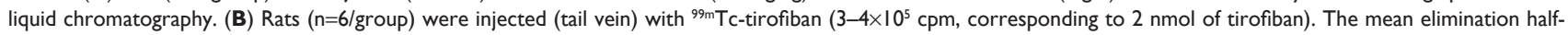
lives $\left(t_{1 / 2}\right)$ are depicted.

Abbreviation: DVT, deep venous thrombosis.

corresponding to $2.0 \mathrm{nmol}$ of tirofiban), radioactivity accumulated at the site of the induced DVT (Figure 4).

\section{Discussion}

In a strict sense, DVT refers specifically to thrombosis of the deep veins of the lower extremities, where thrombosis of the proximal veins is of a particular interest as a risk factor for the development of pulmonary embolism. Therefore, timely diagnosis and treatment is essential. ${ }^{29,30}$ Since ascending contrast venography, a gold standard for DVT diagnosis, is technically demanding, rather expensive and associated with complications, alternative strategies have been developed that

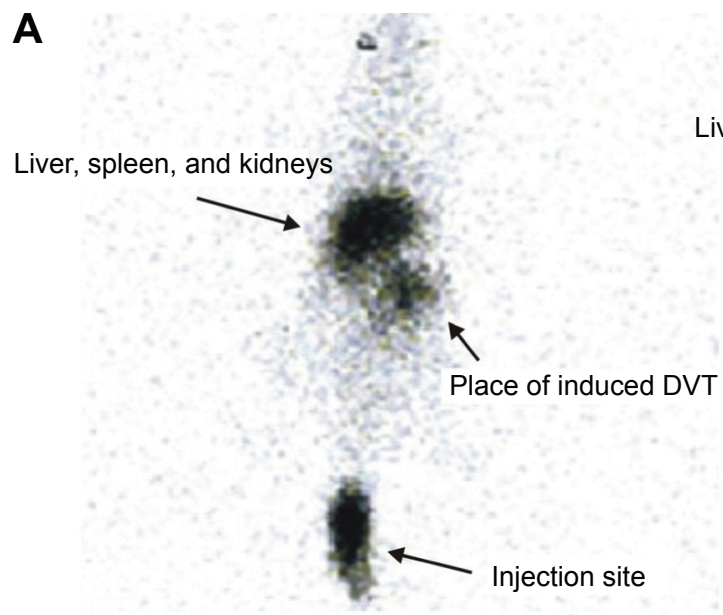

combine clinical judgment (Wells' score), laboratory findings (d-dimer), and noninvasive imaging (ultrasound). However, the diagnostic algorithm is rather complex with still a considerable level of uncertainty. ${ }^{31}$ Imaging methods based on radiolabeled peptides or peptidomimetics that bind to specific platelet receptors have long been suggested as a potentially feasible approach to the early diagnosis of thromboembolic events. ${ }^{32,33}$ The first peptide labeled with radioactive ${ }^{99 \mathrm{~m}} \mathrm{Tc}$ was apticid, and attempts have been made to label abciximab as well as small peptidomimetics that recognize a specific fibrinogen-binding site through the RGD sequence (ArgGly-Asp), such as tirofiban and eptifibatide..$^{34,35}$ For several

B Liver, spleen, and kidneys
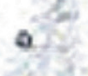
reasons, in this study, we focused on DVT, tirofiban, and ${ }^{99 m}$ Tc: 1) DVT is the third most common cardiovascular disease with an annual incidence estimated at $\sim 100-200 / 100,000$ inhabitants and with a high recurrence rate;29 2 ) tirofiban is a high-affinity platelet GPIIb/IIIa receptor antagonist with a convenient property for a potential diagnostic tool - it rapidly dissociates from its binding site and is rapidly eliminated, and its antiaggregation effect diminishes rapidly upon ending an infusion. Consequently, a bolus iv injection is not likely to affect platelet aggregation and thus compromises the diagnostic process and 3) ${ }^{99 \mathrm{~m}} \mathrm{Tc}$ is an inexpensive, readily available radionuclide with appropriate gamma decay efficiently detected by a gamma camera. The present results demonstrate that ${ }^{99 m}$ Tc-labeled tirofiban retained two important features the ability to bind to platelets (rat and human) and a rapid elimination after an iv bolus injection comparable to that of the unlabeled molecule. The present results are in-line with dose identified in rats and dogs during preclinical development of tirofiban. ${ }^{36}$ Moreover, elimination kinetics apparently was not affected by the existence of DVT (a condition with "activated platelets" as opposed to intact animals). A certain limitation of the present observations lies with the fact that the potential effect of ${ }^{99 \mathrm{~m}} \mathrm{Tc}$ labeling on the in vivo antiplatelet effect of tirofiban was not directly investigated. Also, the antiplatelet effect of the dose selected for imaging studies $(2.0 \mathrm{nmol} /$ rat) was not directly evaluated. However, in vitro studies ${ }^{37}$ clearly indicated only a slight inhibitory effect of tirofiban at a concentration of $10 \mathrm{nM}$ on ADP-induced platelet aggregation. Considering the steady state volume of distribution of tirofiban in rats of $\sim 360 \mathrm{~mL}$ in a $220-250 \mathrm{~g}$ weighing rat, ${ }^{38}$ the selected dose was reasonably expected to yield blood concentrations $<10 \mathrm{nM}$. Moreover, considering the molecular weight of tirofiban hydrochloride (495.1), the selected in vivo dose corresponded to $\sim 1.0 \mu \mathrm{g} /$ animal or $\sim 4-5 \mu \mathrm{g} / \mathrm{kg}$ in a 220-250 g weighing rats. In humans, the antiplatelet effect of tirofiban is achieved by a bolus iv dose (over 5 minutes) of $25 \mu \mathrm{g} / \mathrm{kg}$, followed by a prolonged infusion. ${ }^{16}$ By alometric scaling, this loading human dose corresponds to $155 \mu \mathrm{g} / \mathrm{kg}$ in a rat. Therefore, it is highly unlikely that the administered dose of ${ }^{99 \mathrm{~m}}$ Tc-tirofiban had any antiplatelet effect. This is further substantiated by the fact that the imaging findings were comparable at 30 minutes (time of the first onset of antiplatelet effect $)^{16}$ and at 60 minutes after administration of ${ }^{99 \mathrm{~m}}$ Tc-tirofiban. ${ }^{37}$

\section{Conclusion}

The present results strongly indicate that ${ }^{99 \mathrm{~m}} \mathrm{Tc}$ labeling of tirofiban hydrochloride has no impact on its essential pharmacodynamics and pharmacokinetic properties (radioactive tirofiban has a similar pharmacokinetic profile as nonradioactive tirofiban) and that a low, "sub-therapeutic" dose of ${ }^{99 \mathrm{~m}}$ Tc-tirofiban could enable early diagnosis of DVT.

\section{Disclosure}

The authors report no conflicts of interest in this work.

\section{References}

1. Fuster V, Badimon L, Badimon JJ, Chesebro JH. The pathogenesis of coronary artery disease and the acute coronary syndromes. $N \mathrm{Engl}$ J Med. 1992;326(4):242-250.

2. Jagroop IA, Mikhailidis DP. The effect of Tirofiban on fibrinogen/ agonist-induced platelet shape change and aggregation. Clin Appl Thromb Hemost. 2008;14(3):295-302.

3. Christie DJ, Avari T, Carrington LR, et al. Platelet Function Testing by Aggregometry: Approved Guideline. CLSI Guideline H58-A (ISBN 1-56238-683-2). Clinical and Laboratory Standards Institute, Wayne, PA; 2008.

4. Hayward CP, Moffat KA, Rab A, et al. Development of North American consensus guidelines for medical laboratories that perform and interpret platelet function testing using light transmission aggregometry. Am J Clin Pathol. 2010;134:955-963.

5. Leslie M. Cell biology. Beyond clotting: the powers of platelets. Science. 2010;328(5978):562-564.

6. Brass L. Understanding and evaluating platelet function. Hematology Am Soc Hematol Educ Program. 2010;2010:387-396.

7. Picker SM. In-vitro assessment of platelet function. Transfus Apheresis Sci. 2011;44(3):305-319.

8. Giordano A, D'Angelillo A, Romano S, et al. Tirofiban induces VEGF production and stimulates migration and proliferation of endothelial cells. Vascul Pharmacol. 2014;61(2-3):63-71.

9. Hashemzadeh M, Furukawa M, Goldsberry S, Movahed MR. Chemical structures and mode of action of intravenous glycoprotein IIb/IIIa receptor blockers: a review. Exp Clin Cardiol. 2008;13(4):192-197.

10. Jayasundera TG, Feldman DN, Marmur JD. Tirofiban-induced coronary thrombosis. J Invas Cardiol. 1999;11(3):138-140.

11. Lannetta L, Puddu PE, Cuturello D, Saladini A, Pellicano M, Schiariti M. Is there still a role for glycoprotein IIb/IIIa antagonists in acute coronary syndromes? Cardiol Res. 2013;4(1):1-7.

12. King S, Short M, Harmon C. Glycoprotein IIb/IIIa inhibitors: the resurgence of tirofiban. Vascul Pharmacol. 2016;78:10-16.

13. Brunton LL, Lazo JS, Parker KL. Goodman and Gilman's, The Pharmacological Basis of Therapeutics. 11th ed. New York: The McGraw Hill Co.; 2006.

14. Kumar A, Herrmann HC. Tirofiban: an investigational platelet glycoprotein IIb/IIIa receptor antagonist. Expert Opin Investig Drugs. 1997;6(9): 1257-1267.

15. Anon. Tirofiban hydrochloride. Drugs Future. 1995;20:897-901.

16. http://www.accessdata.fda.gov/drugsatfda_docs/label/1998/20912lbl. pdf. Accessed October 24, 2014.

17. Medicure Pharma. Aggrastat (Tirofiban Hydrochloride) Injection Premixed and Injection Prescribing Information. Somerset, NJ: Medicure Pharma; 2007.

18. Darkovska Serafimovska M, Janevik-IvanovskaE, Arsova-SarafinovskaZ, Djorgoski I, Ugresic N. Development and validation of reverse phase high performance liquid chromatographic method for determination of tirofiban in serum. Int J Pharm. 2014;4(4):115-120.

19. Kulkarni S, Dopheide SM, Yap CL, et al. A revised model of platelet aggregation. J Clin Invest. 2000;105(6):783-791.

20. Smith JW, Steinhubl SR, Lincoff AM, et al. Rapid platelet-function assay - an automated and quantitative cartridge-based method. Circulation. 1999;99(5):620-625. 
21. Holmes MB, Kubbani S, Terrien C, Sobel B, Schneider D. Quantification by flow cytometry of the efficacy and interindividual variation of platelet inhibition induced by treatment with tirofiban and abciximab. Coron Artery Dis. 2001;12(3):245-253.

22. Simon DI, Liu CB, Ganz P, et al. A comparative study of light transmission aggregometry and automated bedside platelet function assay in patients undergoing percutaneous coronary intervention and receiving abciximab, eptifibrate, or tirofiban. Catheter Cardiovasc Interv. 2001; 52(4):425-432.

23. Lister-James J, Mauer A. Thrombus imaging with a technetium 99m labeled, activated platelet receptor binding peptide. J Nucl Med. 1996; 213:207.

24. Pearson DA, Lister-James J, McBride WJ, et al. Thrombus imaging using technetium-99m-labeled high-potency GPIIb/IIIa receptor antagonists. Chemistry and initial biological studies. J Med Chem. 1996; 39(7):1372-1382.

25. Callas JW, Fareed DDJ. A survey of animal models to develop new and novel antithrombotic agents. In: Sasahara AA, Loscalzo JL, editors. New Therapeutic Agents in Thrombosis and Thrombolysis. New York: Marcel Dekker; 1997:9-28.

26. Herbert JM, Bernat A, Maffrand JP. Importance of platelets in experimental venous thrombosis in the rat. Blood. 1992;80(9):2281-2286.

27. Bougie DW, Wilker PR, Wuitschick ED, et al. Acute thrombocytopenia after treatment with Tirofiban or eptifibatide is associated with antibodies specific for ligandoccupied GPIIb/IIIa. J Am Soc Hematol. 2002; 100(6):2071-2076.

28. Hardoff R, Braegelmann F, Zanzonico P, et al. External imaging of atherosclerosis in rabbits using an 123 I-labeled syntetic peptide fragment. J Clin Pharmacol. 1993;33(11):1039-1047.

29. Konstantinides S, Torbicki A, Agnelli G, et al; Task Force for the Diagnosis and Management of Acute Pulmonary Embolism of the European Society of Cardiology (ESC). ESC Guidelines on the diagnosis and management of acute pulmonary embolism. Eur Heart J. 2014;35(43): 3033-3069.
30. Kearon C, Akl E, Comerota AJ, et al. Antithrombotic therapy for VTE disease. Chest. 2012;141(2 suppl):e419S-e494S.

31. National Institute for Health and Clinical Excellence. Venous Thromboembolic Disease: the Management of Venous Thromboembolic Disease of Thrombophilia Testing. Clinical Guideline. Methods Evidence and Recommendations; London 2012.

32. Janevic E, Tadzer IS. Tc-99m labelling of platelets using diethyldithiocarbamate or 2,5-dihydroxy-benzoic acid. Period Biol. 1989;91: 409-411.

33. Schneider DJ. Anti-platelet therapy: glycoprotein IIbIIIa antagonists. Br J Clin Pharmacol. 2011;72(4):672-682.

34. Trajkovski R, Milenkov V, Dukovski R, Janevic E, Tadžer IS. Obeležavanje humanih trombocita sa dietill-ditiokarbamat Tc-99m (DDC). Bilten Hemat Transf. 1989;17:21-25.

35. van Rensburg WJ, Roodt JP, Lamprecht S, Meiring SM, Badenhorst PN. Tirofiban versus abciximab: tirofiban is administered at suboptimal dosages when evaluated in an arterial thrombosis model in non-human primates. Clin Exp Med. 2012;12(4):257-263.

36. Yeung J, Holinstat M. Newer agents in antiplatelet therapy: a review. J Blood Med. 2012;3:33-42.

37. Darkovska SM, Janevik-Ivanovska E, Ugresic N, Djorgoski I. Imaging of deep venous thrombosis using radioactive-labeled tirofiban. Bratisl Med J. 2015;116(10):621-626, 6.

38. Vickers $\mathrm{S}$, Theoharides $\mathrm{AD}$, Arison $\mathrm{B}$, et al. In vitro and in vivo studies on the metabolism of tirofiban. Drug Metab Dispos. 1999;27(11): $1360-1366$.
Drug Design, Development and Therapy

\section{Publish your work in this journal}

Drug Design, Development and Therapy is an international, peerreviewed open-access journal that spans the spectrum of drug design and development through to clinical applications. Clinical outcomes, patient safety, and programs for the development and effective, safe, and sustained use of medicines are the features of the journal, which

\section{Dovepress}

has also been accepted for indexing on PubMed Central. The manuscript management system is completely online and includes a very quick and fair peer-review system, which is all easy to use. Visit http://www.dovepress.com/testimonials.php to read real quotes from published authors. 